\title{
Mortality from brain cancer and leukaemia among electrical workers
}

\author{
Dana P Loomis, D A Savitz
}

\begin{abstract}
The relation of brain cancer and mortality from leukaemia to electrical occupations was investigated in a case-control study based on all deaths in 1985 and 1986 in the 16 states in the United States that report occupational data from death certificates to the national vital statistics registry. The case series comprised all 2173 men who died of primary brain cancer (International Classification of Diseases-9 ((ICD-9) code 191) and all 3400 who died of leukaemia (ICD-9 codes 204-208). Each was matched with 10 controls who died of other causes in the same year. Men employed in any electrical occupation had age race adjusted odds ratios (ORs) of 1.4 (95\% confidence interval (CI) 1.1-1.7) for brain cancer and 1.0 (95\% CI 0.8-1.2) for leukaemia, compared with men in all other occupations. Brain cancer odds ratios were larger for electrical engineers and technicians (OR $2 \cdot 7,95 \%$ CI 2.1-3.4), telephone workers (OR 1·6, 95\% CI 1·1-2·4), electric power workers (OR 1.7, 95\% CI 1·1-2.7), and electrical workers in manufacturing industries (OR 2.1, 95\% CI 1.3-3.4). There was some evidence of excess leukaemia among the same groups (ORs of 1.1-1.5) despite absence of an association for all electrical workers. The excess of deaths from brain cancer was concentrated among men aged 65 or older, whereas leukaemia was associated with electrical work only among younger decedents and those with acute lymphocytic leukaemia. These results from a large and geographically diverse population corroborate reports of increased mortality from brain cancer among electrical workers, but gives only limited support to suggestions of excess deaths from leukaemia.
\end{abstract}

The possible association between electromagnetic fields and cancer has been of interest for nearly a decade, beginning with Wertheimer and Leeper's

Department of Epidemiology, School of Public Health, University of North Carolina, Chapel Hill, NC 27599-7400, USA

D P Loomis, D A Savitz report on childhood cancer and residential exposures. ${ }^{1}$ This report also noted, in passing, evidence of an occupational leukaemia hazard as well. Widespread attention to occupational exposures began with Milham's letter to the New England Journal of Medicine, which suggested a possible increase in deaths from leukaemia among electrical workers. ${ }^{2}$ This precipitated a series of reports that tended to corroborate the association. ${ }^{3}$

Brain cancer among electrical workers has received less attention than leukaemia, but empirical support for an increase in risk may be more consistent. Studies of brain cancer and occupation in Maryland, ${ }^{4}$ east Texas, ${ }^{5}$ and selected areas in the northeast United States ${ }^{6}$ have all found sizeable associations with one or more groups of electrical workers.

The hypothesis that exposure to non-ionising electromagnetic radiation $(50-60 \mathrm{~Hz}$ power frequencies as well as higher frequencies) generated by a variety of electrical devices might enhance the likelihood of developing cancer has been advanced to explain these occupational associations. Experimental confirmation of such a hypothesis is absent, but evidence of biological responses to low level electromagnetic fields is growing ${ }^{7}$ and pathways for a carcinogenic effect of such fields have been postulated. ${ }^{8}$

In previous epidemiological studies of electrical workers, regular and presumably prolonged exposure to electromagnetic radiation was imputed based on job titles-for example, electrician or radio and television repairman. Although such "electrical workers" were arbitrarily identified and there is uncertainty regarding their actual exposure to electromagnetic fields, the identification of health risks among men holding particular job titles is of value even if agents or factors other than those originally of interest are ultimately found to be responsible. In addition, the use of job titles as a means of identifying occupational hazards allows examination of large data bases containing information on job title and cause specific mortality. The present study makes use of a large recently released data set to evaluate further the role of electrical work in the aetiology of brain cancer and leukaemia.

Subjects and methods

Subjects were selected from 1985 and 1986 mortality 
Table 1 Exposure classification for electrical and non-electrical occupations based on United States Census Bureau 1980 occupational categories

\begin{tabular}{|c|c|c|}
\hline Exposure group & Code & Description \\
\hline Electrical: & $\begin{array}{l}055 \\
213 \\
228 \\
523 \\
525 \\
526 \\
527 \\
529 \\
533 \\
555 \\
575 \\
576 \\
577 \\
695 \\
773\end{array}$ & $\begin{array}{l}\text { Electrical and electronic engineers } \\
\text { Electrical and electronic technicians } \\
\text { Broadcast equipment operators } \\
\text { Electronic repair, communication, and industrial equipment } \\
\text { Data processing equipment repairers } \\
\text { Household appliance and power tool repairers } \\
\text { Telephone line installers and repairers } \\
\text { Telephone installers and repairers } \\
\text { Miscellaneous electrical and electronic equipment repairers } \\
\text { Supervisors, electricians, and power installers and repairers } \\
\text { Electricians } \\
\text { Electrician apprentices } \\
\text { Electric power installers and repairers } \\
\text { Power plant operators } \\
\text { Motion picture projectionists }\end{array}$ \\
\hline $\begin{array}{l}\text { Non-electrical: } \\
\text { Exposure to o }\end{array}$ & $\begin{array}{l}\text { cupational carcinog } \\
043-083 \\
084-106 \\
203-235 \\
445-447 \\
448-455 \\
473-499 \\
503-699 \\
703-889\end{array}$ & $\begin{array}{l}\text { sible } \\
\text { Architects, engineers, and scientists } \\
\text { Health diagnosing, assessing, and treating occupations } \\
\text { Technicians and related support occupations } \\
\text { Health service occupations } \\
\text { Cleaning and building service occupations } \\
\text { Farming, forestry, and fishing occupations } \\
\text { Precision production, craft, and repair occupations } \\
\text { Operators, fabricators, and labourers }\end{array}$ \\
\hline $\begin{array}{l}\text { Non-electrical: } \\
\text { Exposure to o }\end{array}$ & $\begin{array}{l}\text { cupational carcinog } \\
003-037 \\
113-199 \\
243-389 \\
403-444,456-469\end{array}$ & $\begin{array}{l}\text { kely } \\
\text { Executive, administrative, and managerial occupations } \\
\text { Professional specialty occupations, except architects, engineers, scientists, and health } \\
\text { diagnosing, assessing, and treating } \\
\text { Technical, sales, and administrative support occupations, except technicians and } \\
\text { related support } \\
\text { Service occupations, except cleaning and building services and health services }\end{array}$ \\
\hline
\end{tabular}

data tapes supplied by the United States National Center for Health Statistics (NCHS) for the 16 states (Colorado, Georgia, Kansas, Kentucky, Maine, Missouri, Nebraska, Nevada, New Hampshire, Ohio, Oklahoma, Rhode Island, South Carolina, Tennessee, Utah, and Wisconsin) that code occupation and industry data from death certificates and report them to the NCHS. Coding is done systematically according to the 1980 United States Census Bureau occupational classification system. ${ }^{9}$ A total of 480909 deaths occurred among men aged 20 or more but 22170 men (5\%) who were not residents of the state in which they died, and 48088 men $(10 \%)$ with uninformative occupational data (occupation unknown or coded as retired, student, volunteer, or never worked) were excluded from the study, yielding 410651 potential subjects.

All 2173 men in this group who died from primary malignant brain tumours (International Classification of Diseases-9 (ICD-9) code 191) and all 3400 who died from any of the leukaemias (ICD-9 codes 204-208) who met the eligibility criteria formed the case series. For each case, 10 eligible persons who died in the same year from any cause except brain cancer or leukaemia were selected as controls.

The coded occupation and industry from the death certificates were used to classify the cases and con- trols with regard to occupational exposure to electromagnetic fields. A list of "electrical" occupations potentially subjecting workers to such exposures was compiled from previous studies ${ }^{4011}$ with some additions from our review of the Census Bureau occupational categories (table 1). In order to examine patterns of risk among the diverse occupations that make up the broad category of electrical workers, they were subdivided into several occupational and industrial groups expected to be more uniform with regard to exposures to electromagnetic fields and other agents. Occupational subgroups were defined by Census Bureau codes as electrical and electronic engineers and technicians (census codes 055, 213), equipment repairers (codes 523, 525, 526, 533), telephone and telephone line installers and repairers (codes 527, 529), electricians and their apprentices (codes 575, 576), and electric power installers and repairers (code 577). For analysis by industrial sector, all workers with electrical occupations as defined in table 1 in construction (code 60), manufacturing (codes 100-392), communication and utilities (codes 442-462), and business and repair services (codes 721-760) constituted the exposed group.

For most analyses all occupations not classified as electrical were considered as unexposed to electromagnetic fields. To allow for some control of 
Table 2 Odds ratios for association of brain cancer and leukaemia with employment in electrical $v$ other occupations

\begin{tabular}{|c|c|c|c|c|c|}
\hline \multirow{3}{*}{$\frac{\text { Disease }}{\text { Brain cancer: }}$} & \multirow{3}{*}{$\begin{array}{l}\text { Unexposed group } \\
\text { All others } \\
\text { Possible only§ } \\
\text { Unlikely only§ }\end{array}$} & \multicolumn{2}{|c|}{ No unexposed } & \multirow[b]{2}{*}{ OR $(95 \% C I) \dagger$} & \multirow[b]{2}{*}{ OR $(95 \% C I) \ddagger$} \\
\hline & & Cases & Controls & & \\
\hline & & $\begin{array}{r}2098 \\
1283 \\
815\end{array}$ & $\begin{array}{r}21246 \\
14583 \\
6663\end{array}$ & $\begin{array}{ll}1.6 & (1 \cdot 2-2 \cdot 0) \\
1.8 & (1 \cdot 4-2 \cdot 3) \\
1.3 & (1.0-1 \cdot 6)\end{array}$ & $\begin{array}{ll}1.4 & (1 \cdot 1-1 \cdot 7) \\
1.5 & (1 \cdot 1-1 \cdot 9) \\
1.2 & (0.9-1 \cdot 5)\end{array}$ \\
\hline Leukaemia: & $\begin{array}{l}\text { All others } \\
\text { Possible only } \\
\text { Unlikely only }\end{array}$ & $\begin{array}{l}3324 \\
2137 \\
1187\end{array}$ & $\begin{array}{l}33248 \\
24937 \\
10448\end{array}$ & $\begin{array}{ll}1.0 & (0 \cdot 8-1 \cdot 3) \\
1.1 & (0.9-1 \cdot 4) \\
0.9 & (0.7-1 \cdot 1)\end{array}$ & $\begin{array}{ll}1.0 & (0 \cdot 8-1 \cdot 2) \\
1.0 & (0 \cdot 8-1 \cdot 3) \\
0.9 & (0 \cdot 7-1 \cdot 1)\end{array}$ \\
\hline
\end{tabular}

$\star^{\star}$ Exposed group $=$ all electrical occupations; numbers exposed $=75$ cases of brain cancer and 484 controls, 76 cases of leukaemia and 752 controls.

tCrude estimate.

${ }_{+}^{\ddagger}$ Mantel-Haenszel estimate, adjusted for age and race.

$\S$ Estimated likelihood of exposure to other occupational carcinogens.

possible differences between electrical and other workers in exposure to organic solvents and other occupational carcinogens, the non-electrical occupations were further divided into subgroups judged as "possibly" or "unlikely" to be exposed to such agents (table 1).

Mortality ratios for the association of brain cancer and leukaemia with work in electrical occupations were estimated as the mortality odds ratio (OR). Odds ratios were adjusted for decade of age and race (white, black, other) using the Mantel-Haenszel method $^{12}$ and logistic regression. ${ }^{13}$ Ninety five per cent confidence intervals $(95 \% \mathrm{CIs})$ for the crude and Mantel-Haenszel ORs were estimated by the test based method, ${ }^{14}$ and the formula $\mathrm{CI}=\exp [\beta \pm 1.96$ $(\mathrm{SE}(\beta))$ ], where $\beta$ is the estimated regression coefficient and SE $(\beta)$ is its standard error, was used to derive $95 \%$ CIs for estimates obtained by logistic regression.

\section{Results}

A history of employment in electrical occupations was rare among the men in this study. Among cases, 75 men with brain cancer and 76 with leukaemia had electrical occupations listed on the death certificate, whereas death certificates of 484 brain cancer controls and 752 leukaemia controls ( $2 \%$ of all controls) indicated such occupations. Table 2 shows odds ratios for the association of brain cancer and leukaemia mortality with electrical occupations. When the unexposed group was defined as all non-electrical occupations there was a modest excess of deaths from brain cancer among electrical workers that was reduced slightly after adjustment for age and race. Leukaemia was not associated with electrical work, with or without adjustment.

Restricting the comparison group to either subset of non-electrical occupations defined by likelihood of occupational exposure to other carcinogens gave generally similar results (table 2 ). The ORs for both diseases increased slightly when men with electrical occupations were compared with the non-electrical group consisting only of workers considered as possibly exposed to other occupational carcinogens, and decreased slightly relative to the group containing only those thought unlikely to have had such exposures. This contrast suggests slightly higher background mortality for both diseases in the group unlikely to have been exposed.

Table 3 shows the association of brain cancer and leukaemia with electrical work among men aged 64 or under and 65 or older at death, a crude marker of the likelihood that death occurred while the person was still employed or after retirement. Adjustment for race did not change the estimated ORs or CIs, so only the crude results are shown. The previously noted excess of brain cancer occurred predominantly in the group aged 65 or older and a small excess of leukaemia appeared among those under 65 , with a corresponding deficit among older men.

Table 3 Odds ratios for association mortality from leukaemia and brain cancer with employment in electrical occupations $v$ all others by stratum of age

\begin{tabular}{|c|c|c|c|c|c|c|}
\hline \multirow{3}{*}{$\begin{array}{l}\text { Disease } \\
\text { Brain cancer } \\
\text { Brain cancer }\end{array}$} & \multirow{3}{*}{$\begin{array}{l}\text { Age group } \\
<65 \\
\geqslant 65\end{array}$} & \multicolumn{2}{|c|}{ Exposed } & \multicolumn{2}{|c|}{ Unexposed } & \multirow[b]{2}{*}{$O R(95 \% C I)^{\star}$} \\
\hline & & Cases & Controls & Cases & Controls & \\
\hline & & $\begin{array}{l}41 \\
34\end{array}$ & $\begin{array}{l}176 \\
308\end{array}$ & $\begin{array}{r}1222 \\
876\end{array}$ & $\begin{array}{r}6382 \\
14864\end{array}$ & $\begin{array}{ll}1.2 & (0.9-1.7) \\
1.9 & (1.3-2.7)\end{array}$ \\
\hline $\begin{array}{l}\text { Leukaemia } \\
\text { Leukaemia }\end{array}$ & $\begin{array}{l}<65 \\
\geqslant 65\end{array}$ & $\begin{array}{l}38 \\
38\end{array}$ & $\begin{array}{l}279 \\
479\end{array}$ & $\begin{array}{l}1030 \\
2294\end{array}$ & $\begin{array}{l}10118 \\
23130\end{array}$ & $\begin{array}{ll}1.3 & (0.9-1.7) \\
0.8 & (0.6-1.1)\end{array}$ \\
\hline
\end{tabular}

*Crude estimate. 
Table 4 Odds ratios for association of death from leukaemia with employment in electrical occupations, by leukaemia subtype

\begin{tabular}{|c|c|c|c|c|c|}
\hline \multirow{2}{*}{$\begin{array}{l}\text { Leukaemia cell type } \\
\text { Acute myeloid }\end{array}$} & \multirow{2}{*}{$\frac{I C D-9}{205 \cdot 0}$} & \multicolumn{2}{|l|}{ Cases $\star$} & \multirow{2}{*}{\multicolumn{2}{|c|}{ OR $(95 \% C I) \dagger$}} \\
\hline & & Exposed & Unexposed & & \\
\hline $\begin{array}{l}\text { Acute myeloid } \\
\text { Acute lymphocytic } \\
\text { Other acute } \\
\text { Chronic lymphocytic } \\
\text { Chronic non-lymphocytic } \\
\text { All other leukaemias }\end{array}$ & $\begin{array}{l}205 \cdot 0 \\
204 \cdot 0 \\
206 \cdot 0,207 \cdot 0 \\
204 \cdot 1 \\
205 \cdot 1,206 \cdot 1,207 \cdot 1 \\
-\end{array}$ & $\begin{array}{r}22 \\
6 \\
1 \\
11 \\
11 \\
25\end{array}$ & $\begin{array}{r}881 \\
175 \\
87 \\
789 \\
403 \\
989\end{array}$ & $\begin{array}{l}1 \cdot 1 \\
1 \cdot 5 \\
0 \cdot 5 \\
0 \cdot 6 \\
1 \cdot 1 \\
1 \cdot 1\end{array}$ & $\begin{array}{l}(0 \cdot 7-1 \cdot 7) \\
(0 \cdot 7-3 \cdot 4) \\
(0 \cdot 1-3 \cdot 5) \\
(0 \cdot 3-1 \cdot 1) \\
(0 \cdot 8-1 \cdot 7) \\
(0 \cdot 8-1 \cdot 7)\end{array}$ \\
\hline
\end{tabular}

$\star$ Number of controls; 752 exposed, 33248 unexposed.

†Crude estimate.

Table 4 shows the association of leukaemia cell types with a history of electrical work. Only crude data are shown because adjustment for age and race did not alter the estimates. Among the acute leukaemias, only the lymphocytic form was positively associated with electrical occupations and there was essentially no relation between acute myeloid leukaemia and electrical work. Other acute leukaemias and chronic lymphocytic leukaemia were negatively associated with electrical occupations and other chronic leukaemias and leukaemias of other or uncertain types were unrelated to electrical work. Brain cancer mortality could not be analysed by histological type, because the ICD version used to code cause of death does not provide the required information.

Several subgroups of electrical workers had brain cancer ORs substantially different from one (table 5). After adjustment for age and race, engineers and technicians, telephone workers, and electric power workers had ORs that indicated increased mortality. The residual group of other electrical workers had notably fewer deaths from brain cancer than expected. When the industrial sector was considered (table 5), electrical workers in manufacturing, and com- munications and utilities, also had adjusted ORs greater than unity as did those in the residual category of other industries. The OR was less than expected for electrical workers in construction and near unity for those in business and repair services.

By contrast with brain cancer, no occupational subgroup was strongly associated with leukaemia (table 6). Nevertheless, after adjustment for age and race the three groups with increased mortality from brain cancer had slightly raised ORs for leukaemia, whereas electricians and the residual group had lower than expected mortality. Mortality from leukaemia was substantially raised among electrical workers in the manufacturing sector and, as with brain cancer, the OR was below one among those in the construction industry. The mortality of electrical workers in other industries was essentially as expected.

\section{Discussion}

These results tend to corroborate earlier evidence of a positive association between electrical occupations and mortality from brain cancer. The overall OR of 1.4 for the association of electrical work and brain cancer is consistent with several other studies. ${ }^{4-61516}$ Nevertheless, some studies of comparable size and

Table 5 Odds ratios for association of death from brain cancer by industrial sector and occupational group

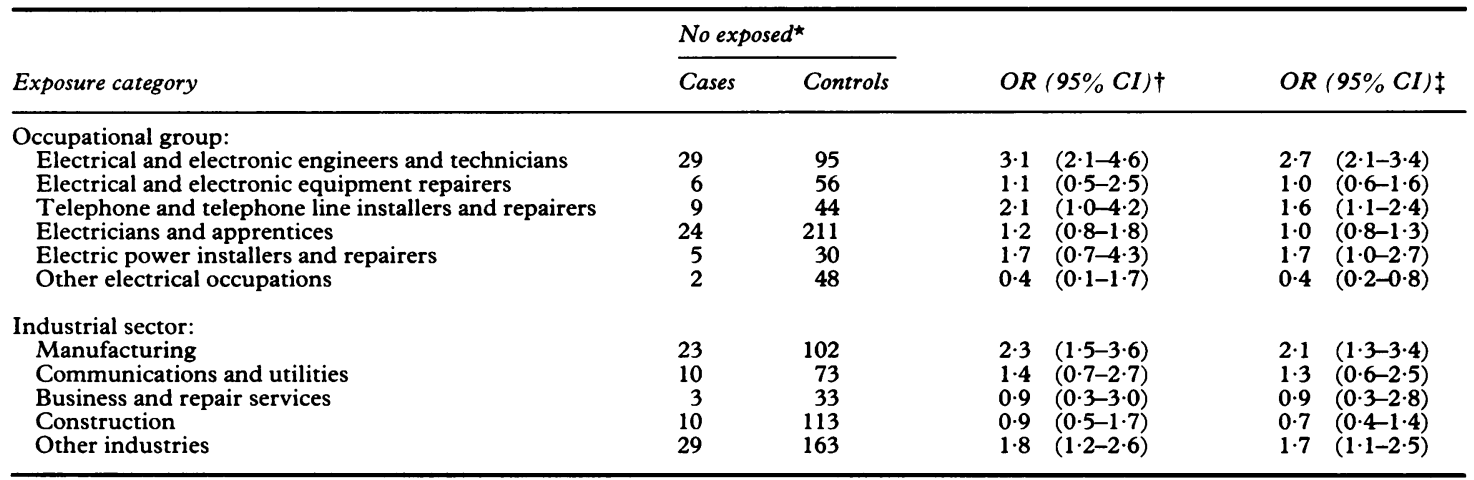

*Unexposed group = all non-electrical occupations; cases $=2098$, controls $=21246$.

+Crude estimate.

$\ddagger$ Logistic regression estimate adjusted for age and race. 
Table 6 Odds ratios for association of deaths from leukaemia by industrial sector and occupational group

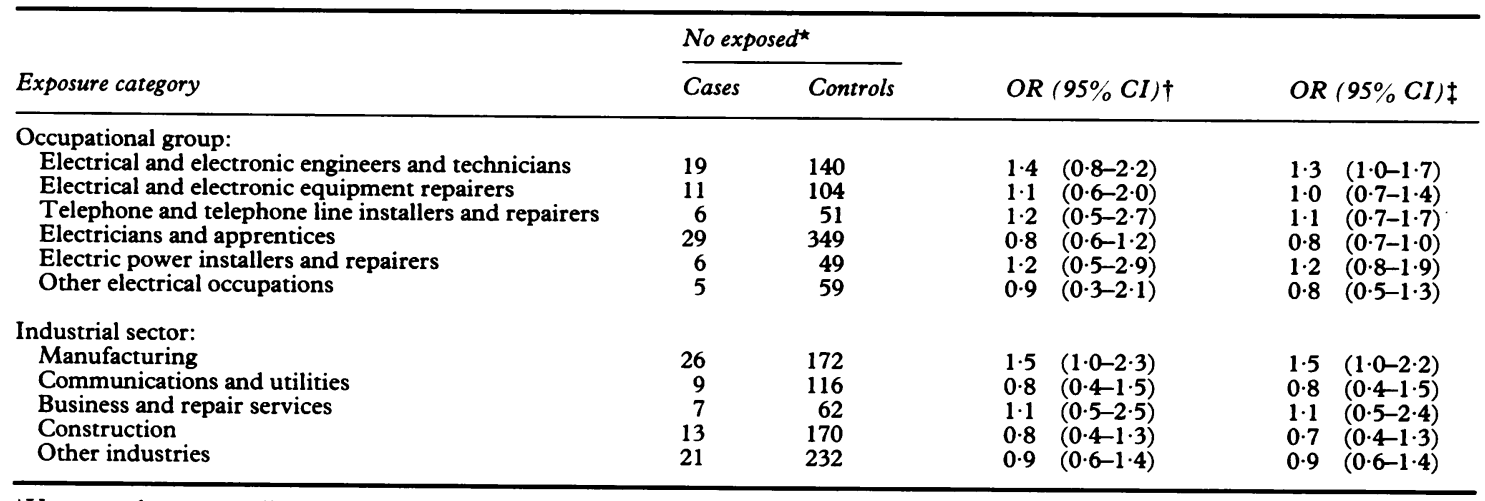

*Unexposed group = all non-electrical occupations; cases = 3324, controls = 33248.

+Crude estimate.

$¥$ Logistic regression estimate adjusted for age and race.

quality did not find such evidence. ${ }^{17} 18$ The strength of association was greatest in this study for men over 65 and for electrical engineers and technicians, telephone workers, electric power workers, and electrical workers in manufacturing industries. The enhanced risks for electrical engineers are consistent with results of some other studies, ${ }^{418}$ but most studies did not report results for industries or subsets of electrical occupations.

Our data, however, lend only partial support for the evidence for increased leukaemia mortality among electrical workers. The null results concerning leukaemia among electrical workers as a group contrast with several other published reports. ${ }^{38-20}$ The positive association of leukaemia with electrical work among younger decedents only is opposite to the gradient found among New Zealand electrical workers. ${ }^{18}$ The tendency toward an association only with acute lymphocytic leukaemia in our data also differs from reports of stronger associations with acute myeloid leukaemia ${ }^{3}$ and with chronic rather than acute leukaemia, ${ }^{18}$ although among New Zealand electrical workers, as in this study, risk appeared to be enhanced for lymphocytic rather than myeloid leukaemia. ${ }^{18}$

Modestly raised mortality from leukaemia was also found for electrical engineers and technicians, telephone workers, electric power workers, and electrical workers in the manufacturing sector. Earlier studies did not report data on risk from leukaemia in subgroups defined in this manner. In a synthesis of studies, however, power station operators, power and telephone linemen, electronic technicians, and electrical engineers all had some heightened risk of leukaemia (rate ratios from 1.2 to $1 \cdot 6$ ), but telephone repairers and installers did not (rate ratio $0 \cdot 9){ }^{3}$ The subgroup findings for leukaemia in this study are also supported by the remarkably similar although stronger patterns of brain cancer mortality.

The observed mortality differentials between subgroups of electrical workers may reflect variation in the magnitude of electromagnetic field exposures among them, but there have been no comprehensive surveys of exposure sustained in specific occupations or industries. Existing data suggest that electricians and powerline workers have substantially higher exposure relative both to non-electrical workers and those in other electrical occupations. ${ }^{2122}$ These studies, however, obtained measurements on few workers in selected predominantly electrical occupations and did not adequately characterise the exposure of workers in Census Bureau occupational or industrial categories.

An important consideration in evaluating these results and integrating them with previous findings concerns the accuracy of exposure assessment based on job titles. The job title "electrical worker" is of questionable sensitivity and specificity as a marker of aetiologically relevant exposure to any particular agent. It undoubtedly fails to capture everyone chronically exposed to electromagnetic fields above background levels-for example, office workers spending extensive time near photocopiers-and falsely attributes exposures to others such as electrical engineers who do not work with energised equipment. The design of this study and most others ensured that exposure misclassification was similar for cases and controls, thus predicting a dilution of the effect measure. ${ }^{23}$ As the same methods were used to classify exposures for cases of brain cancer and leukaemia and controls in this study, the results for both diseases would be equally affected by any such bias if the same exposures affected both outcomes.

Exposures to other potentially carcinogenic agents such as solvents and polychlorinated biphenyls may occur in a number of electrical occupations and could in principle, explain high mortality from cancer among workers in such occupations. Some investigators have indeed found indications that these agents are likely to account for the observed excesses of cancer. ${ }^{6}$ Exposures to other carcinogens cannot be completely separated from electromagnetic field 
exposures by job titles alone, but an attempt in this study to control for confounding by exposure to such agents through the use of alternate comparison groups of non-electrical workers tended to suggest negative rather than the expected positive confounding. This indication of apparently higher mortality from brain cancer and leukaemia among a group consisting predominantly of managers and professionals presumably unexposed to chemical carcinogens is not easily explained but it is consistent with reports of raised mortality from brain cancer among similar workers elsewhere ${ }^{24}$ although leukaemia patterns appeared to differ by cell type. ${ }^{25}$

The temporal relation between exposure and disease defines another critical dimension of exposure assignment. Job titles on death certificates do not provide any indication of the duration of employment or the time between termination of that job and death. Whatever the critical time window might be for an aetiologically effective exposure, the unspecified and probably heterogenous periods represented in these data would dilute the measure of any underlying causative effects. ${ }^{26}$

Although this study shares limitations with previous investigations, the data set on which it is based has some advantages over those used previously: in particular its broad geographic origin and relatively large numbers of cases. The series of 75 cases of brain cancer and 76 of leukaemia among electrical workers exceeds the number in all but three previous surveys. ${ }^{112728}$

In summary, our results enhance the justification for further studies of brain cancer, although they provide only limited support with regard to leukaemia. The purpose of this study and those that preceded it was to identify exposures worthy of the costly effort required for a more complete evaluation. Studies that are of sufficient size and quality to determine the effect of electromagnetic fields on the incidence of the rather rare outcomes of brain cancer and leukaemia are challenging, but essential, in that no number of replications using a basic design relying on job titles as surrogate measures of exposure will resolve questions of aetiology or public health importance. Improved epidemiological studies and further assessment of occupational and general population exposure to electromagnetic fields are clearly needed; our results should encourage the use of this data set for examining potential occupational influences on cancer and other fatal outcomes, despite the inability to identify exposures to specific agents.

We thank Robert Kleckner for help with management of data and Andrew Rowland and Eric Johnson for their careful reviews and suggestions for improvement of the manuscript.
1 Wertheimer N, Leeper E. Electrical wiring configurations and childhood cancer. Am J Epidemiol 1979;109:273-84.

2 Milham S. Mortality from leukaemia in workers exposed to electrical and magnetic fields. N Engl J Med 1982;307:249.

3 Savitz DA, Calle EE. Leukemia and occupational exposure to electromagnetic fields: review of epidemiologic surveys. $J$ Occup Med 1987;29:47-51.

4 Lin RS, Dischinger PC, Conde J, Farrell KP. Occupational exposure to electromagnetic fields and the occurrence of brain tumors. J Occup Med 1985;27:413-9.

5 Speers MA, Dobbins JG, Miller VS. Occupational exposures and brain cancer mortality: a preliminary study of east Texas residents. Am J Ind Med 1988;13:629-38.

6 Thomas TL, Stolley PD, Stemhagen A, et al. Brain tumor mortality risk among men with electrical and electronics jobs: a case-control study. J Natl Cancer Inst 1987;79:233-8.

7 US Congress, Office of Technology Assessment. Biological effects of power frequency electric and magnetic fields-background paper. Washington: US Government Printing Office, 1989. (OTA-BP-E-53.)

8 Byus CV, Pieper SE, Adey WR. The effects of low-energy $60-\mathrm{Hz}$ environmental electromagnetic fields upon the growth-related enzyme ornithine decarboxylase. Carcinogenesis 1987;8: 1385-9.

9 US Department of Commerce, Bureau of the Census. Alphabetical index of industries and occupations: 1980 census of population. Washington: US Government Printing Office, 1982.

10 Wright WE, Peters JM, Mack TM. Leukaemia in workers exposed to electrical and magnetic fields. Lancet 1982;ii: $1160-1$.

11 Milham S Jr. Mortality in workers exposed to electro-magnetic fields. Environ Health Perspect 1985;62:297-300.

12 Mantel N, Haenszel W. Statistical aspects of the analysis of data from retrospective studies of disease. J Natl Cancer Inst 1959;22:719-48.

13 Harrell FE Jr. The LOGIST procedure. In: Hastings RP, ed SUGI supplemental library user's guide. 5th ed. Cary NC: SASS Institute Inc, 1986:269-94.

14 Miettinen OS. Estimability and estimation in case-referen studies. Am J Epidemiol 1976;103:226-35.

15 Milham S Jr. Increased mortality in amateur radio operators due to lymphatic and hematopoietic malignancies. Am J Epidemiol 1988;127:50-4

16 Preston-Martin S, Henderson BE, Peters JM. Descriptive epidemiology of central nervous system neoplasms in Los Angeles County. Ann NY Acad Sci 1982;381:202-8.

17 McLaughlin JK, Malker HSR, Blot WJ, et al. Occupational risks for intracranial gliomas in Sweden. $J$ Natl Cancer Inst 1987;78:253-7.

18 Pearce N, Reif J, Fraser J. Case-control studies of cancer in New Zealand electrical workers. Int J Epidemiol 1989;18:55-9.

19 Stern FB, Waxweiler RA, Beaumont JJ, et al. A case-control study of leukaemia at a naval nuclear shipyard. Am J Epidemiol 1986;123:980-92.

20 Flodin U, Fredriksson M, Axelson O, Persson B, Hardell L. Background radiation, electrical work, and some other exposures associated with acute myeloid leukemia in a casereferent study. Arch Environ Health 1986;41:77-84.

21 Deadman JE, Camus M, Armstrong BG, et al. Occupational and residential $60-\mathrm{Hz}$ electromagnetic fields and high-frequency electric transients: exposure assessment using a new dosimeter. Am Ind Hyg Assoc J 1988;49:409-19.

22 Bowman JD, Garabrant DH, Sobel E, Peters JM. Exposures to extremely low frequency (ELF) electromagnetic fields in occupations with elevated leukemia rates. Applied Industrial Hygiene 1988;3:189-94.

23 Copeland KT, Checkoway H, McMichael AJ, Holbrook RH. Bias due to misclassification in the estimation of relative risk. Am J Epidemiol 1977;105:488-95.

24 Thomas TL, Waxweiler RJ. Brain tumors and occupational risk factors. Scand J Work Environ Health 1986;12:1-15.

25 Pearce NE, Howard JK. Occupation, social class, and male mortality in New Zealand, 1974-8. Int J Epidemiol 1986; 15:456-62.

26 Rothman KJ. Induction and latent periods. Am J Epidemiol 1981;114:253-9.

27 McDowall ME. Leukaemia mortality in electrical workers in England and Wales. Lancet 1983;i:246.

28 Coleman M, Bell J, Skeet R. Leukemia incidence in electrical workers. Lancet 1983;i:982-3.

Accepted 12 February 1990 